\title{
TUNDISH SLAG CAPACITY TO ABSORB INCLUSIONS WHEN USING CALCIUM ALUMINATE BASED COVERING MATERIAL COMBINED WITH RICE HULL ASH*
}

\author{
Márcia Maria da Silva Monteiro Pereira ${ }^{1}$ \\ Marco Túlio Lima² \\ Gérson Tolentino Ferreira ${ }^{3}$ \\ Hervé Tavernier ${ }^{4}$ \\ Jeferson Leandro Klug 5 \\ Nestor Cezar Heck ${ }^{6}$ \\ Detlef Jung ${ }^{7}$
}

\begin{abstract}
Tundish is the last reactor where significant metallurgical operations can still be done. Calcium aluminate slags are able to positively contribute to metallurgy considering oxide separation, protection against reoxidation and preclusion of resulphurisation. However, these are poor insulators. When using low melting point slags it is necessary to use another covering material. The deviation from saturation can be used as a measure of absorption capacity. By utilizing computerized construction of ternary and quaternary diagrams it is possible to compare different slags and to find proper slag compositions with reasonable capacity to dissolve inclusions. Objective of the present technical contribution is to evaluate tundish slag capacity to absorb inclusions, considering a particular tundish industrial slag and the changes in its chemical composition during continuous casting of steel. It was observed that slag composition changed during the continuous casting process; this variation is possibly related to interaction between the $\mathrm{CaO}-\mathrm{Al}_{2} \mathrm{O}_{3}$ liquid slag and the rice hull ash layer which is used above it. Computational thermodynamics was used to determine activity of alumina dissolved in liquid slag; it was observed that the variation in slag composition did not change slag capacity to absorb inclusions, since precipitation of $\mathrm{Al}_{2} \mathrm{O}_{3}$ solid phases is not predicted.

Keywords: Inclusions; Tundish slag; Tundish covering materials; Calcium aluminate; Rice hull ash.
\end{abstract}

\footnotetext{
Laboratory Supervisor, IMERYS Steelcasting do Brasil, SP, Brazil.

Customer Service Engineer, IMERYS Steelcasting do Brasil, SP, Brazil.

Customer Service Director, IMERYS Steelcasting do Brasil, SP, Brazil.

R\&A Manager, IMERYS Metalcasting France S.A.R.L., Cedex, France

Prof. Dr.-Ing., Universidade Federal do Ceará, CE, Brazil.

Prof. Dr.-Ing., Universidade Federal do Rio Grande do Sul, RS, Brazil.

Managing Director, IMERYS Steelcasting do Brasil, SP, Brazil.
} 


\section{INTRODUCTION}

Tundish is used as a reservoir and distributor for liquid steel from the ladle into the moulds in a multi-strand caster. It is the last reactor where significant metallurgical operations can still be done. As the steel cleanliness has become a main objective for demanding steel grades, the role of the tundish is nowadays both to promote inclusion removal from the liquid steel and to prevent appearance of new often macroscopic inclusions, which are most harmful for steel quality; typically these are reoxidation products formed between the ladle and the mould [1].

Main purpose of the covering materials rice hulls, fly ashes, fly ashes with added soda, and some synthetic covering materials is thermal insulation. A limited metallurgical influence in the form of inclusions absorption is only expected in the case of fly ashes, when considering these materials [2].

Low melting point slags e.g. calcium aluminate ones are able to positively contribute to metallurgy considering oxide separation, protection against reoxidation and preclusion of resulphurisation. However, these are poor insulators. When using low melting point slags it is necessary to use another covering material (above it) for getting better insulation.

The best working method for the tundish covering material, in particular considering the manufacture of low sulphur steels, is to use calcium aluminate based covering slags. Due to the formation of liquid slag the steel is hermetically sealed, avoiding in this way contact with nitrogen of the ambient air. Besides, calcium aluminate slags present good sulphide capacities, which changes insignificantly in case of entrained ladle slag. Therefore, no resulphurisation takes place.

Regarding tundish slags' capacity to absorb inclusions, it depends on many things considering physico-chemical properties of the system and the participating phases. High capacity of slag to absorb inclusions from steel is a key property of a metallurgically active tundish slag. The deviation from saturation can be used as a measure of absorption capacity. By utilizing computerized construction of ternary and quaternary diagrams it is possible to compare different slags and to find proper slag compositions with reasonable capacity to dissolve inclusions [1].

Sophisticated research techniques such as confocal laser scanning microscope, interfacial tension measurements (drop weight method), and double hot thermocouple technique can be used for industrial slags for getting useful information on interfacial reactions and phenomena like inclusions removal and dissolution, including kinetics, and slag emulsification [1,3]. Regarding dissolution kinetics of alumina and $\mathrm{MgO}$-alumina spinel inclusions into industrial tundish slags, great variability is observed in dissolution rates for different slags; in general, experimental measurements show that dissolution is much slower in acid slags than in basic slags, when considering alumina and MgO-alumina inclusions [1]. This information is important since the interval of time for the interaction between steel and tundish slag is relatively short during the industrial process. Depending on slag composition inclusions absorption can be insignificant. Basic Ca-aluminate type slags have potential for wide use due to their chemical stability against the steel - in particular considering the deoxidation reaction $\left(\mathrm{SiO}_{2}\right)+4 / 3 \underline{\mathrm{Al}}=2 / 3\left(\mathrm{Al}_{2} \mathrm{O}_{3}\right)$ inc $+\underline{\mathrm{Si}}-$ and due to their sufficient capacity to absorb inclusions.

Objective of the present technical contribution is to evaluate tundish slag capacity to absorb inclusions, considering a particular tundish industrial slag and the changes in its chemical composition during continuous casting of steel. 


\section{MATERIAL AND METHODS}

For evaluating tundish slag capacity to absorb inclusions computational thermodynamics was used considering industrial data i.e. samples collected in the tundish during production of steel in a Brazilian steelworks. The elemental chemical composition for these samples was determined through X-ray fluorescence technique at Imerys Steelcasting do Brasil laboratory. Then, this information was used as input data for the commercial software FactSage version 6.4 (Universidade Federal do Rio Grande do Sul).

\subsection{Elemental chemical composition analysis}

Initially sample $(0.75 \pm 0.0009 \mathrm{~g})$ and flux $\left(6 \pm 0.0009 \mathrm{~g}\right.$ of $\left.\mathrm{Li}_{2} \mathrm{~B}_{4} \mathrm{O}_{7}\right)$ were heated in a furnace in a platinum crucible at $750{ }^{\circ} \mathrm{C} \pm 15^{\circ} \mathrm{C}$ for removing carbon. Then, sample and flux were melted using a melting device VULCAN VAA 2 (Figure 1), producing a vitreous disc, which was analyzed using an apparatus PHILIPS AXIOS 4KW (Figure 2 ). In this way the elemental composition of the materials was determined by X-ray fluorescence technique.

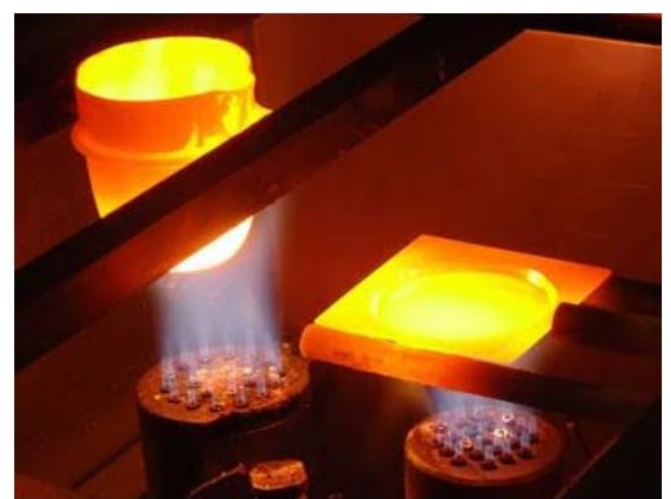

Figure 1. Melting device Vulcan VAA 2

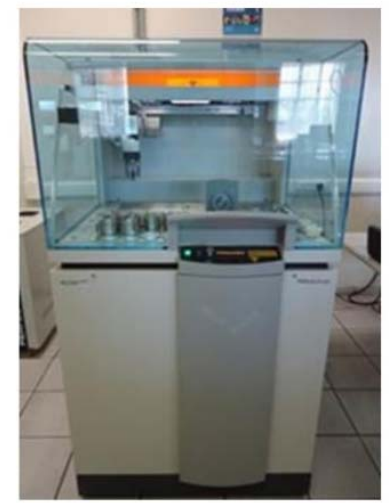

Figure 2. Apparatus Philips Axios 4KW (Imerys Steelcasting do Brasil laboratory)

\subsection{Tundish industrial slags' capacity to absorb inclusions}

In the present work the deviation from saturation was used as a measure of absorption capacity, as suggested by Holappa et al. The equilibrium state for the systems was determined by the 'Gibbs energy minimization method' using the Equilib 
module of the FactSage software (version 6.4). Output of Equilib module gives numeric values related to phase amount, phase composition and component activities. Likewise the phase diagrams were drawn using the Phase Diagram module - the software is described elsewhere by Bale et al [4]. The following three databases were employed: Fact pure substances database (2013); Fact oxide compounds (2013); and Fact oxide solutions (2013).

Two kinds of elemental compositions were used as input data for doing the calculations with FactSage:

(i) the composition of the tundish cover material produced by Imerys Steelcasting do Brasil and used by a Brazilian steelworks (as delivered)

(ii) elemental chemical composition of tundish slag samples, which were collected during production of steel

\section{RESULTS AND DISCUSSION}

\subsection{Elemental chemical composition analysis}

Elemental compositions for tundish cover material as delivered to the steelworks, and tundish slag samples collected during production of steel are shown at Table 1 (minor amounts of impurities were ignored).

Table 1. Elemental compositions for tundish cover material and for tundish slag samples. OC=original composition (as delivered). Two samples were collected per each run (start and end)

\begin{tabular}{|c|c|c|c|c|c|c|c|c|c|c|c|c|c|}
\hline wt\% & OC & \multicolumn{2}{|c|}{ Run 1} & \multicolumn{2}{|c|}{ Run 2} & \multicolumn{2}{|c|}{ Run 3} & \multicolumn{2}{|c|}{ Run 4} & \multicolumn{2}{|c|}{ Run 5} & \multicolumn{2}{|c|}{ Run 6} \\
\hline $\mathrm{CaO}$ & 58.0 & 41.5 & 39.9 & 37.9 & 36.5 & 24.0 & 28.4 & 20.9 & 21.6 & 36.0 & 36.4 & 34.3 & 33.7 \\
\hline $\mathrm{Al}_{2} \mathrm{O}_{3}$ & 30.2 & 24.7 & 27.7 & 26.1 & 25.9 & 22.9 & 20 & 18. & 22.8 & 20.9 & 20 & 20.7 & 20.1 \\
\hline $\mathrm{SiO}_{2}$ & 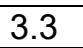 & 22.9 & 22.7 & 26.9 & 28.1 & 35.3 & 41.0 & 31.5 & 35.0 & 27.4 & 26.6 & 28.7 & 30.8 \\
\hline $\mathrm{MgO}$ & 1.5 & 2.9 & 2.4 & 2.2 & 2.3 & 5.2 & 3.4 & 7.9 & 7.3 & 8.4 & 8.3 & 8.4 & 8.0 \\
\hline
\end{tabular}

Considering that liquid slag is not a good insulator it was necessary to use during the industrial tests rice hull ash above it. The authors suppose that a mixture occurred between the layers, increasing the silica content of the liquid slag. This assumption was used in the following calculations.

\subsection{Tundish industrial slags' capacity to absorb inclusions}

In the present work, the activity of the $\mathrm{Al}_{2} \mathrm{O}_{3}$ component in the liquid slag was determined. This is a very important entity, because it can be directly related with the slag capacity to absorb and remove the harmful non-metallic alumina inclusions from the liquid steel.

The activity of the $\mathrm{Al}_{2} \mathrm{O}_{3}$ component in the liquid slag is readily determined by the software when performing the determination of the equilibrium state for any system under study which includes the liquid slag phase alone or in combination with other liquid of solid phases in that state of equilibrium. This however is not the correct activity, since the reference state in the determination method is usually pure $\left(\mathrm{Al}_{2} \mathrm{O}_{3}\right)$ liquid slag. In order to get the truthful activity some careful modifications must be introduced in the calculation procedure - the extent of each is dependent of the used software. The correct activity reference state that must be used in the present case, in order to accomplish the need and to match the alumina 'saturation' measure (or driving force), is the alpha alumina solid phase. 
Two industrial cases were studied in this work: (i) the as delivered material and (ii) the mixed slag obtained from the calcium aluminate slag and rice hull ash (compositions at Table 1). The $\mathrm{Al}_{2} \mathrm{O}_{3}$ activity determination with reference in the alpha alumina phase was carried out for the pure calcium aluminate flux and the results showed the value of 0.01 . Besides the liquid slag, at $1550^{\circ} \mathrm{C}$ the other only phase present was solid $\mathrm{CaO}$. The flux composition is such that solid $\mathrm{CaO}$ represents only $13 \mathrm{wt} . \%$ of the system mass at that temperature, Figure 3 . During the production of steel material composition changes, wandering to a place were only liquid slag subsists, Figure 4 . Nevertheless, the $\mathrm{Al}_{2} \mathrm{O}_{3}$ activity shows a slightly increase to 0.17 - still a small activity value.

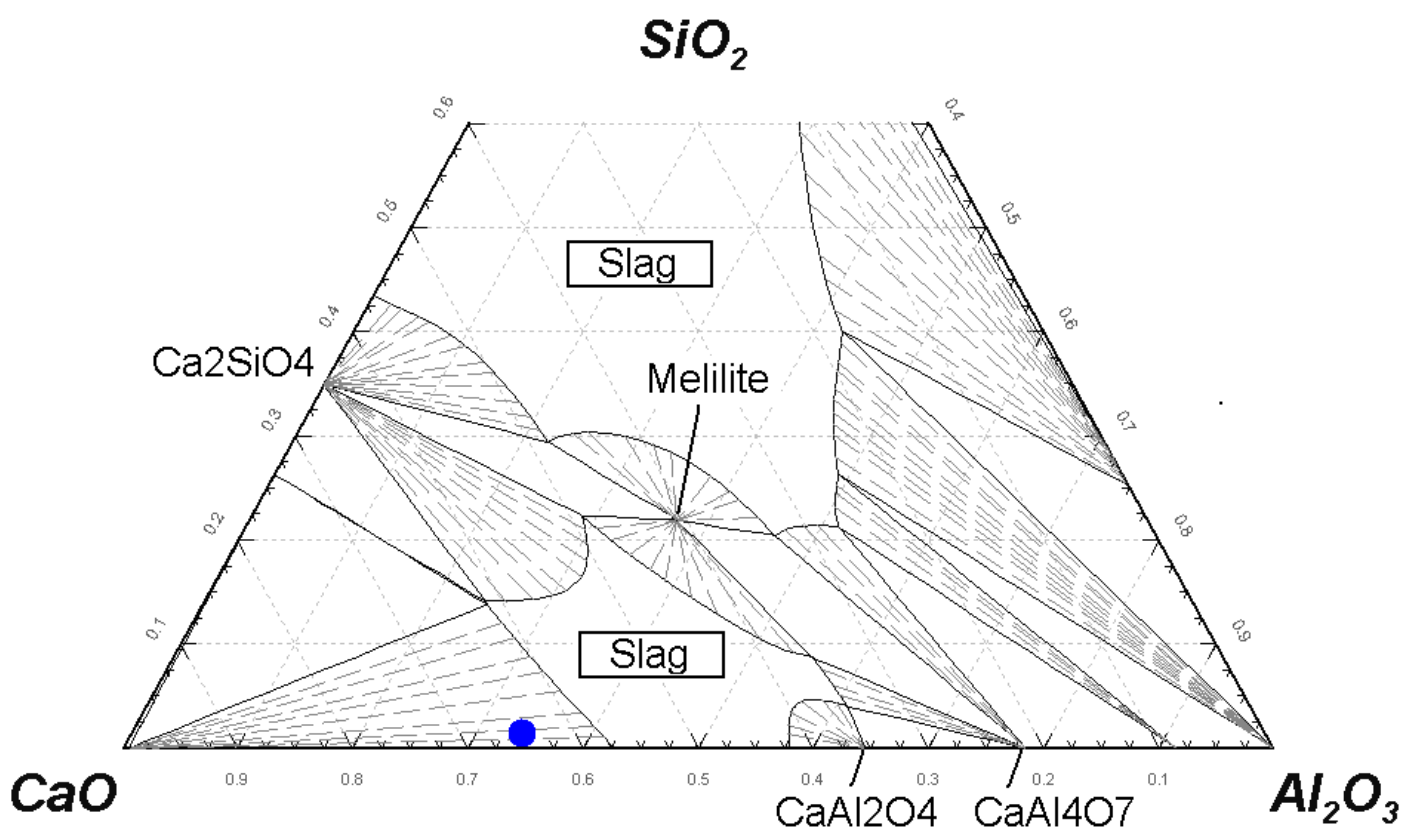

Figure 3. System CAS (wt. \%) at $1550^{\circ} \mathrm{C}$; blue dot = original mold slag composition (Note: all concentrations must be multiplied by $1 / 0.95$ in order to convert it to actual figures); $13 \%$ solids (CaO)

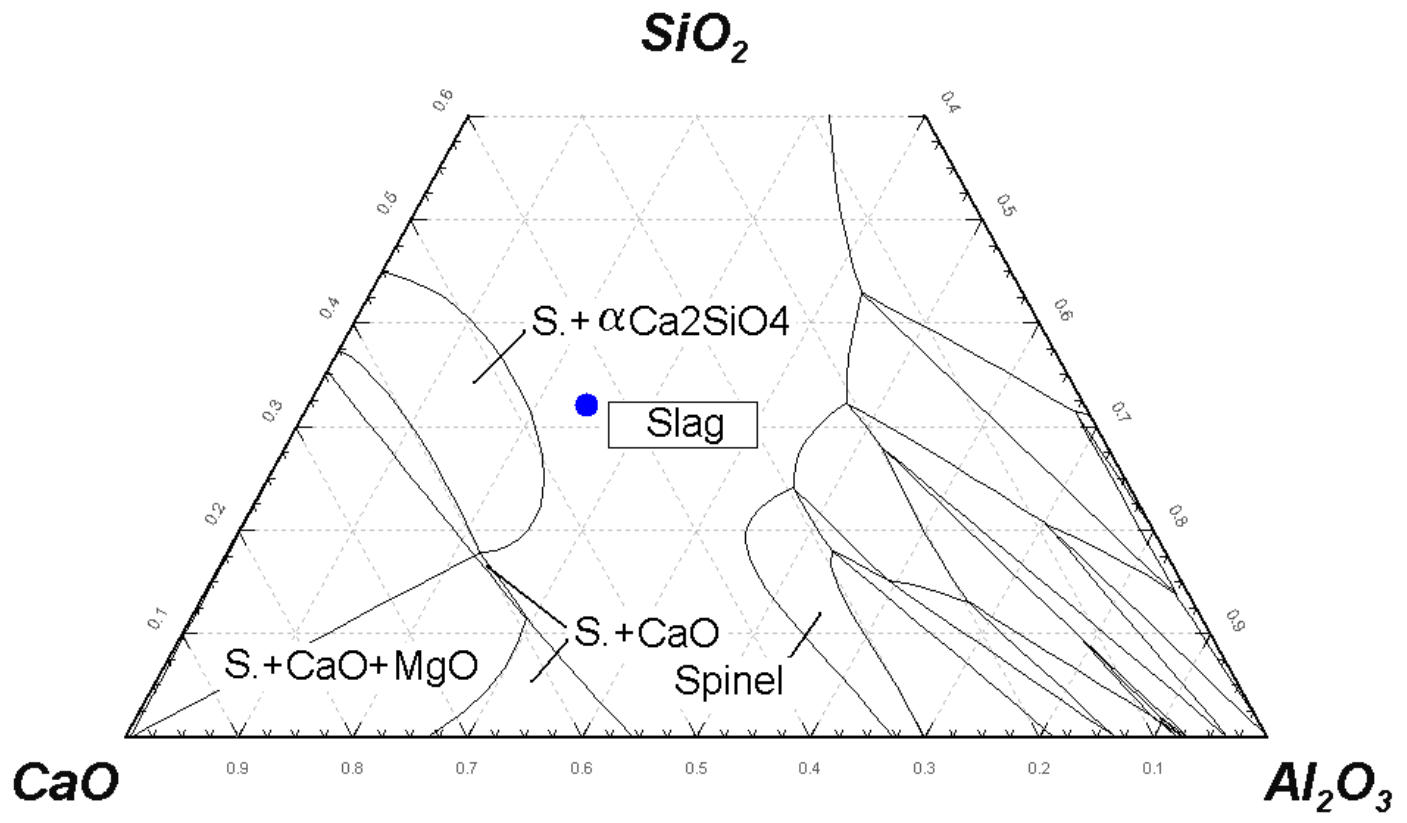

Figure 4. System CASM (wt.\%) with 5 wt. $\% \mathrm{MgO}$ at $1550{ }^{\circ} \mathrm{C}$; blue dot = mold slag composition after rice hull ash addition (Note: all concentrations must be multiplied by $1 / 0.95$ in order to convert it to actual figures); Slag = S = 100\% liquid slag 
These determinations show that the ability of the flux to absorb and remove the harmful non-metallic alumina inclusions from the liquid steel is high and in the event of having $\mathrm{SiO}_{2}$ (from rice hull ash) added to the slag which is in direct contact with steel, tundish industrial slags' capacity to absorb inclusions remains.

\section{CONCLUSION}

- Considering the elemental composition of the tundish cover material produced by Imerys Steelcasting do Brasil, it was observed that its composition changed during continuous casting process, according to X-ray fluorescence analysis; this variation is possibly related to interaction between the $\mathrm{CaO}-\mathrm{Al}_{2} \mathrm{O}_{3}$ liquid slag and the rice hull ash layer which is used above it.

- Computational thermodynamics was used to determine activity of alumina dissolved in liquid slag; it was observed, according to the calculations, that the variation in slag composition did not change slag capacity to absorb inclusions, since precipitation of $\mathrm{Al}_{2} \mathrm{O}_{3}$ solid phases is not predicted.

\section{REFERENCES}

1 Holappa, L., et al., Active Tundish Slag. Steel Research International, 2013. 84(7).

2 Pereira, M.M.S.M., et al., Tundish flux practice: comparison between rice hull ash and fly-ash based tundish flux considering some relevant thermodynamic properties, in 20th IAS Steel Conference. 2014: Rosario, Santa Fe, Argentina.

3 Klug, J.L., Crystallisation control for fluorine-free slags using the Single Hot Thermocouple Technique / available in http://www. bibliotecadigital.ufrgs.br/da. php?nrb=000863376\&loc $=2012 \& /=c 2 c 154 f 9197 e$ 51f7, in Fakultät 5 / PPGE3M. 2012, TU Bergakademie Freiberg and Universidade Federal do Rio Grande do Sul (bi-national doctorate): Freiberg (Saxony, Germany) and Porto Alegre (Rio Grande do Sul, Brazil).

4 Bale, C. W. et al. FactSage Termochemical Software and Databases. Calphad, 2002. 26(2). 